\title{
Transpiration Cooling Using Liquid Water
}

\author{
Arnold van Foreest* and Martin Sippel* \\ DLR, German Aerospace Center, 28359 Bremen, Germany \\ Ali Gülhan $\ddagger$ and Burkard Esser $\stackrel{ \pm}{\sharp}$ \\ DLR, German Aerospace Center, 51170 Cologne, Germany \\ and \\ B. A. C. Ambrosius \pm and K. Sudmeijer $\underline{\underline{8}}$ \\ Delft University of Technology, 2629 HS Delft, The Netherlands
}

DOI: $10.2514 / 1.39070$

\begin{abstract}
At the German Aerospace Center (DLR), a possible solution for handling extreme aerothermodynamic heat loads has been investigated. The solution involves an innovative new way of transpiration cooling, using liquid water. The concept has been tested at the arc heated wind-tunnel section of DLR. The test campaign will be described and the results will be compared with transpiration cooling using a gas as a coolant.
\end{abstract}

\section{Introduction}

$\mathbf{A}$ CTIVE cooling options such as transpiration cooling have the potential to reduce heat loads on hypersonic vehicles, allowing thinner leading edges and sharper noses. Aerodynamic performance of such vehicles can thus be greatly improved. An example of such a vehicle is the SpaceLiner, which is currently under investigation at the Space Launcher System Analysis (SART) department of DLR [1- $\underline{1}-\underline{0}$.

Using fluids as a coolant, the temperatures of the SpaceLiner can be limited. For transpiration cooling a certain coolant mass is required to cool down the vehicle during its flight. Transpiration cooling using a gas (such as nitrogen) has already been studied for different concepts [7]. To reduce overall system mass it is important to use a coolant with a high cooling capacity per unit mass. Such a coolant could be liquid water. Together with the wind-tunnel department at DLR, a test campaign in the arc heated wind-tunnel $\mathrm{L} 2 \mathrm{~K}$ has been set up to investigate the feasibility of using liquid water as a coolant. To verify the advantage of water compared to gas, additional tests were carried out using nitrogen gas as a coolant.

\section{Transpiration Cooling}

A cooling fluid can flow through a heated surface made out of a porous material. The fluid absorbs heat by convection and thus cools the material down. Usually, a gas is used as the coolant. A liquid has the advantage that the heat of vaporization can be used as an additional cooling mechanism. Water is an attractive liquid because it has an extremely high heat of vaporization. Liquids will not become hotter than their boiling temperature. In the case of water, this boiling temperature is $100^{\circ} \mathrm{C}$ at 1 bar and increases proportionally to the pressure. If water remains in its liquid state during the transportation through the porous material, the convective cooling will be very efficient due to the large temperature difference of liquid water and the material when it is not exposed to cooling. When a material with sufficient porosity is used, it will be cooled down to approximately the boiling temperature of the water. To prevent water from

Presented as Paper 4034 at the 39th AIAA Thermophysics Conference, Miami, FL, 25-28 June 2007; received 2 July 2008; revision received 1 April 2009; accepted for publication 2 April 2009. Copyright (C) 2009 by DLRSART. Published by the American Institute of Aeronautics and Astronautics, Inc., with permission. Copies of this paper may be made for personal or internal use, on condition that the copier pay the $\$ 10.00$ per-copy fee to the Copyright Clearance Center, Inc., 222 Rosewood Drive, Danvers, MA 01923; include the code 0887-8722/09 and \$10.00 in correspondence with the CCC.

*Engineer, Space Launcher System Analysis (SART).

${ }^{\dagger}$ Scientist, Windtunnel Department.

Professor, Faculty of Aerospace Engineering.

${ }^{\S}$ Engineer, Faculty of Aerospace Engineering. evaporating within the porous material, new water has to be supplied at a sufficiently high mass flow rate. The higher the heat required for vaporization, the lower the coolant mass flow can be.

The amount of heat which is necessary to evaporate $1 \mathrm{~kg}$ of water depends on the initial temperature of the water, the surrounding pressure, and the heat of vaporization. The heat of vaporization is the additional heat needed for the phase change from liquid to gas.

To vaporize an amount of water, it must first be heated up to the boiling temperature. The energy required for this is defined by the specific heat of water, $C_{\text {water }}=4186 \mathrm{~J} / \mathrm{kg} \cdot \mathrm{K}$. Assuming the water will be supplied at a temperature of $293 \mathrm{~K}$ and that the boiling temperature is $373 \mathrm{~K}$ (at $1 \mathrm{bar}$ ), the temperature difference $\Delta T=$ $80 \mathrm{~K}$. To heat $1 \mathrm{~kg}$ of water up to the boiling temperature the energy supplied must be as follows: $C_{\text {water }} * \Delta T=334.9 \mathrm{~kJ} / \mathrm{kg}$. Then, the phase change occurs. This requires an additional $2260 \mathrm{~kJ} / \mathrm{kg}$ (at $1 \mathrm{bar}$ ). As can be seen the heat of vaporization is much more than the energy that is required to heat up water to a boiling temperature.

Using a liquid as a coolant introduces a capillary pressure in the porous material. This pressure will cause water to flow into regions where no water is present. This capillary action will therefore distribute the liquid over the porous material. A simplified model of capillary action in a porous material can be made by assuming a porous material is made up of a bundle of tubes with a certain radius [8]. As soon as a capillary tube has completely filled with water, there will be no more capillary action. The water level in the material will drop once water evaporates at the surface. The capillary tubes are no longer completely filled with water and capillary action will start again. Consequently new water is automatically supplied to the surface at exactly the required mass flow rate.

The evaporation of the water has an additional cooling effect. The vapor enters the boundary layer, creating a protective layer which blocks the incoming heat flux. This effect is called "blocking" [1]. A schematic representation of this cooling principle is given in Fig. 1.

\section{Wind-Tunnel Test Preparations}

\section{A. L2K and L3K Arc Heated Wind Tunnels}

The cooling concept described above was tested at DLR's arc heated wind-tunnel section. The $\mathrm{L} 2 \mathrm{~K}$ and $\mathrm{L} 3 \mathrm{~K}$ arc heated wind tunnels at DLR are especially designed for high enthalpy flows. An arc heater is used to give the flow its high enthalpy. The wind tunnels have a long history in qualifying thermal protection systems. For example, they have been used in the Hermes, ASTRA, X-38, and MSTP programs [9]. The gas species can be varied. Thus it is possible not only to simulate Earth's reentry, but also, for example, a Mars entry. A schematic view of the wind tunnels is given in Fig. 2.

The L3K has a maximal electrical power supply of $6 \mathrm{MW}$. This generates enthalpies up to $25 \mathrm{MJ} / \mathrm{kg}$ at reservoir pressures between 


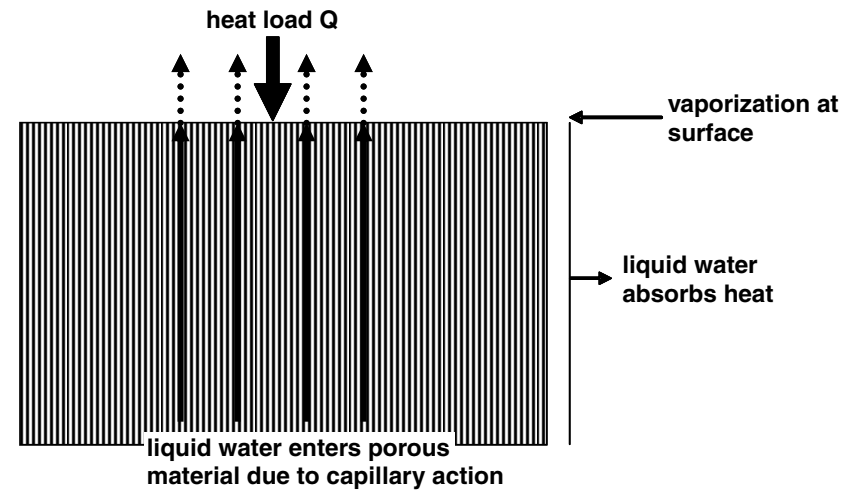

Fig. 1 Cooling principle.

0.15 and 1.8 MPa. The throat diameter can be varied between 200, 300 , and $400 \mathrm{~mm}$ providing Mach numbers between 5 and 10 at Reynolds numbers up to $10^{5} / \mathrm{m}$. Models with a size of $280(\mathrm{~W}) \times$ $350(\mathrm{~L}) \times 70 \mathrm{~mm}^{3}(\mathrm{H})$ can be tested in the homogeneous hypersonic flowfield of this facility. In the stagnation point configuration, pressures up to $350 \mathrm{hPa}$ can be achieved.

The test facility $\mathrm{L} 2 \mathrm{~K}$, with a maximum electrical power of 1.4 MW, can achieve stagnation pressures up to $150 \mathrm{hPa}$. The different combinations of throat diameters of 14, 20, 25, and $29 \mathrm{~mm}$ with exit diameters of 100, 200, and $300 \mathrm{~mm}$ provide Mach numbers between 4 and 8 at Reynolds numbers up to $10^{4} / \mathrm{m}$. Models with a size of $150(\mathrm{~W}) \times 250(\mathrm{~L}) \times 70 \mathrm{~mm}^{3}(\mathrm{H})$ can be tested in the homogeneous hypersonic flowfield of this facility. The wind-tunnel performance parameters are given in Table $\underline{1}$.

\section{B. Model Construction}

To test the liquid water cooling principle, three different nose cone models were made out of a porous material called Procelit 170 (P170). This material consists of $91 \% \mathrm{Al}_{2} \mathrm{O}_{3}$ and $9 \% \mathrm{SiO}_{2}$. Procelit was chosen because of its high porosity, its ability to withstand temperatures of up to $2000 \mathrm{~K}$, and the ease with which it can be manufactured and shaped. The nose cone models used have a varying nose radius, the smallest radius being $1 \mathrm{~cm}$, the middle radius being $1.75 \mathrm{~cm}$, and the largest radius being $2.5 \mathrm{~cm}$. The nose radius was varied to investigate the influence of model geometry on the cooling efficiency. Inside the models, a reservoir has been drilled out. The models were connected to a stagnation probe holder. A copper tube enters the reservoir for water supply, and the water mass flow can be adjusted using a valve. The models and a cross-sectional view of a model fixed to the stagnation probe holder are shown in Fig. 3 .

\section{Temperature Measurement}

The influence of the cooling was observed by measuring the temperature changes on the surface of the models. Surface temperatures were measured using an infrared camera. To determine the temperature with an infrared camera, the emissivity of the surface needs to be known. The energy radiated by an arbitrary body can be related to the energy radiated by a blackbody at the same wavelength and the same temperature by introducing the emissivity coefficient. The amount of energy radiated per unit time per unit surface area by a blackbody is related to temperature according to Planck's law:

$$
E(\lambda)=\frac{2 \pi h c^{2}}{\lambda^{5}[\exp (h c / k T \lambda)-1]}
$$

where $c$ is the speed of light, $\lambda$ the wavelength, $k$ the Boltzmann constant $\left(1.3806505 \times 10^{-23} \mathrm{~J} \cdot \mathrm{K}^{-1}\right), \quad h$ is Planck's constant $\left(6.6260693 \times 10^{-34} \mathrm{~J} \cdot \mathrm{s}\right)$, and $T$ the temperature.

The total amount of energy radiated by a blackbody can be obtained by integrating Planck's law over the entire electromagnetic spectrum:

$$
E_{\mathrm{tot}}=\int_{0}^{\infty} E(\lambda) \mathrm{d} \lambda=\sigma T^{4}
$$

where

$$
\sigma=\frac{2 \pi^{5} k^{4}}{15 h^{3} c^{2}}=5.670400 \times 10^{-8} \mathrm{~J} \cdot \mathrm{s}^{-1} \cdot \mathrm{m}^{-2} \cdot \mathrm{K}^{-4}
$$

is the Stefan-Boltzmann constant.

The energy radiated at a specific wavelength by an arbitrary body can now be related to the energy radiated by a blackbody at the same wavelength and same temperature by introducing the emissivity $\operatorname{coefficient} \varepsilon_{\lambda}$. The energy radiated by this body at the wavelength of interest is then

$$
E(\lambda)=\varepsilon_{\lambda} \frac{2 \pi h c^{2}}{\lambda^{5}[\exp (h c / k T \lambda)-1]}
$$

The total energy radiated by an arbitrary body can again be found by integration over the entire electromagnetic spectrum, where it has to be taken into account that $\varepsilon_{\lambda}$ can change for different wavelengths:

$$
E_{\mathrm{tot}}=\int_{0}^{\infty} \varepsilon_{\lambda}(\lambda) E(\lambda) \mathrm{d} \lambda=\varepsilon_{\mathrm{tot}} \sigma T^{4}
$$

In case of the Procelit 170 material, a graph of the spectral emissivity coefficient is given in Fig. $\underline{4}$. A blackbody radiating at a temperature

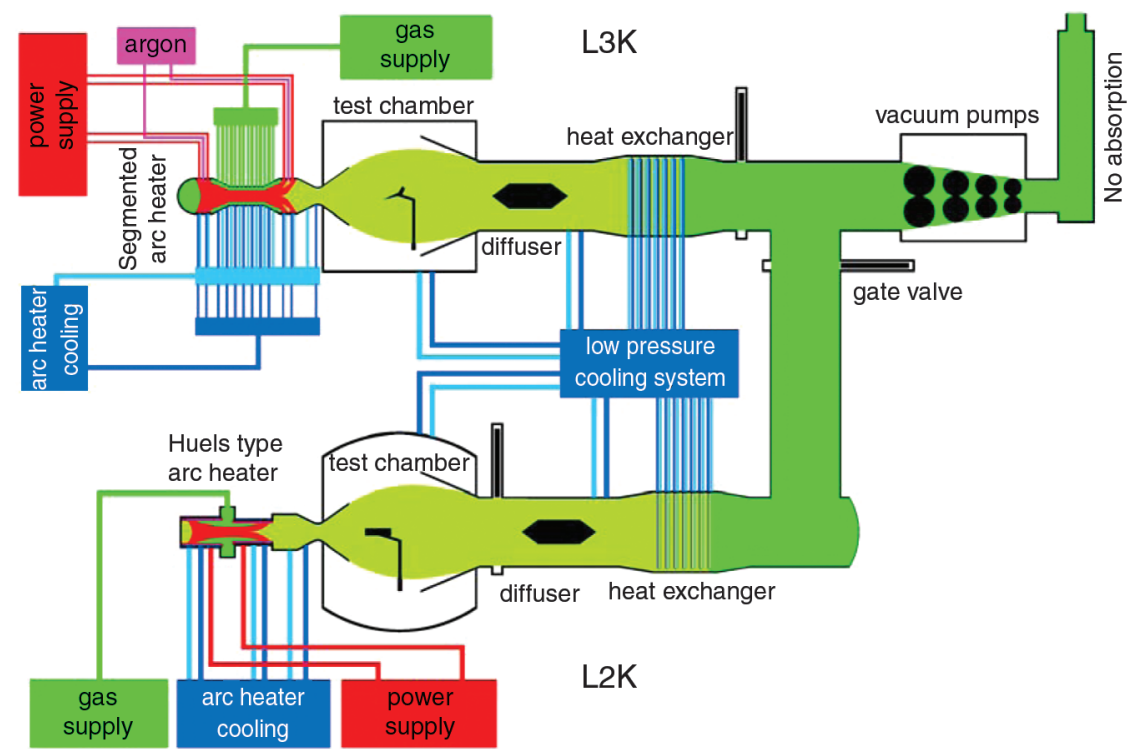

Fig. 2 Schematic view of wind-tunnel facility. 
Table 1 Performance of L2K and L3K wind tunnels

\begin{tabular}{lcc}
\hline \hline & L2K & L3K \\
\hline Nozzle exit diameter, mm & $100,200,300$ & $100,200,300,400$ \\
Mach number, - & $4-8$ & $5-10$ \\
Reynolds number, /m & $<10^{4}$ & $<10^{5}$ \\
Pitot pressure, $\mathrm{hPa}$ & $5-150$ & $15-350$ \\
Total enthalpy, MJ/kg & $3-25$ & $6-25$ \\
Cold wall heat flux, $\mathrm{kW} / \mathrm{m}^{2}$ & $<2000$ & $<4000$ \\
Test duration, s & $<7200$ & $<1800$ \\
\hline \hline
\end{tabular}

of $2000 \mathrm{~K}$ shows a spectral energy distribution seen in Fig. 5. The energy radiated by Procelit 170 at a specific wavelength can be obtained by multiplying the spectral energy for a blackbody with the spectral emissivity of Procelit 170. This is also shown in Fig. 5. The total energy radiated for the blackbody and Procelit 170 is determined by integration over the entire electromagnetic spectrum. Finally, the total emissivity is obtained by dividing the total energy radiated by Procelit 170 by the total energy radiated by the blackbody. For a temperature of $2000 \mathrm{~K}$, this results in a total emissivity of 0.266 .

The emissivity coefficient for the infrared camera can be obtained by following the same procedure, but as the infrared camera only measures the energy radiated over the wavelength spectrum from 8 to $12 \mu \mathrm{m}$, only integration from 8 to $12 \mu \mathrm{m}$ is required. This results in an emissivity of 0.94 at a temperature of $2000 \mathrm{~K}$.

The procedure was repeated for different temperatures. The results are presented in Table 2 .

An important conclusion is that the emissivity in the spectrum of the infrared camera shows almost no dependence on temperature.
This is important because it is only possible to set one emissivity coefficient when using the infrared camera. Temperature over the model surfaces will vary, and if the emissivity would be temperature dependent the measurements over the model surface would not be reliable.

During cooling, the models are soaked with water which could change the emissivity of the surface. Figure 6 shows the emissivity of water and ice. Water and ice are almost perfect black radiators. Their spectral emissivity is higher than 0.95 over the entire $8-12 \mu \mathrm{m}$ spectrum. The emissivity coefficient over this spectrum will therefore be a bit higher than the one for Procelit 170, so the addition of water will increase the emissivity coefficient of the models slightly. Because the emissivity coefficient of Procelit 170 is also very high (0.94), the change will be limited. In addition it will be shown in this paper that the soaking will lead to large temperature drops. The temperature declines to values so low that the infrared camera is not able to measure the temperature anymore. Therefore, the change in the emissivity coefficient due to the water is neglected.

\section{Preliminary Testing}

The L2K wind tunnel was used for the complete test campaign. Although its performance is less than the $\mathrm{L} 3 \mathrm{~K}$, its operation is more straightforward. Because there was no experience with testing this new cooling method, operating simplicity was chosen above performance.

Tests were carried out with all the models. Surface temperature drop of the models was observed using an infrared camera.

Before any reliable tests could be performed, certain test settings had to be investigated and tried out such as, for example, the best way of installing measurement equipment and the water mass flow
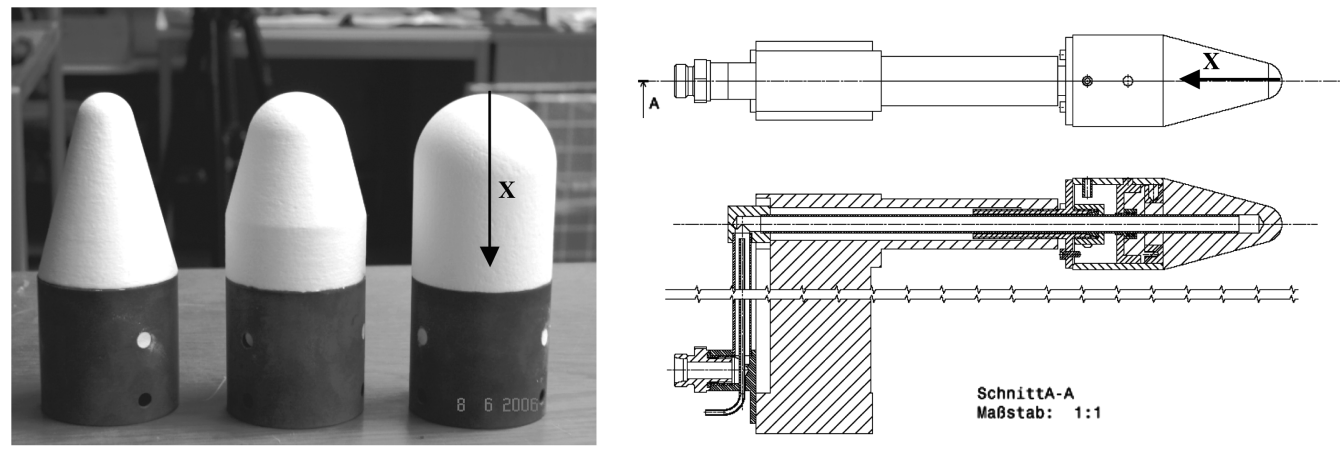

Fig. 3 Wind-tunnel models [1].

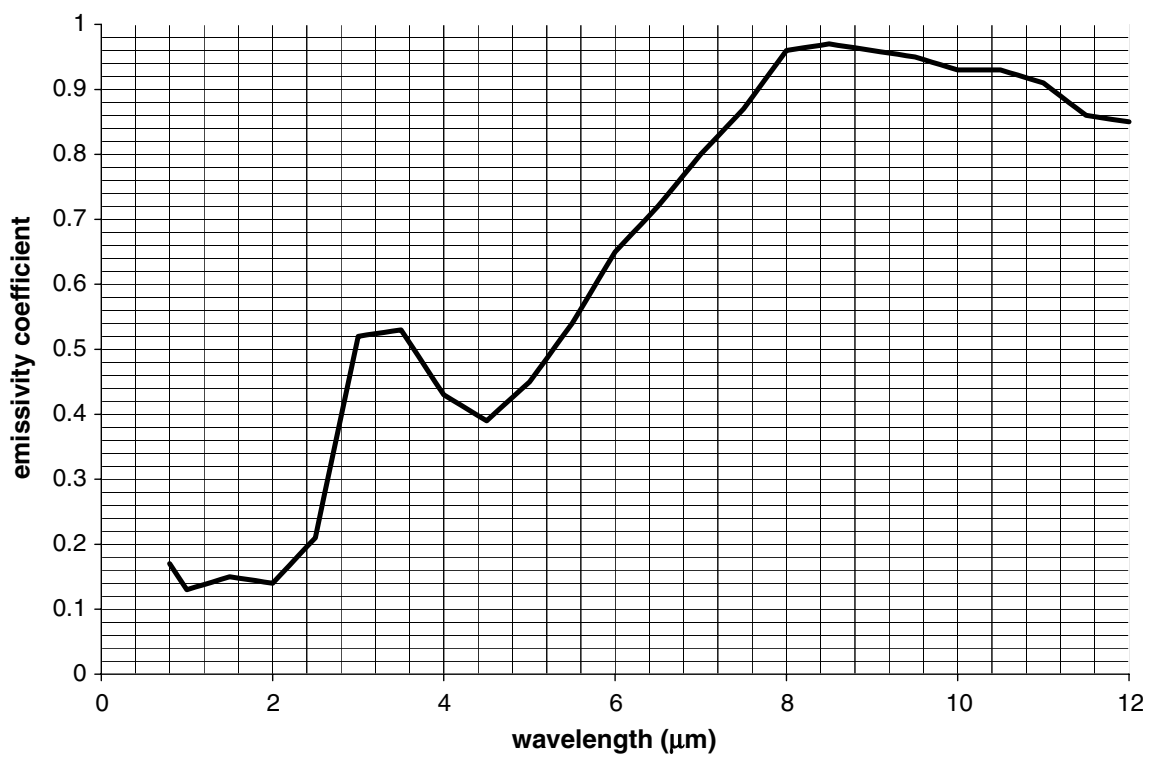

Fig. 4 Spectral emissivity of Procelit 170 [15]. 


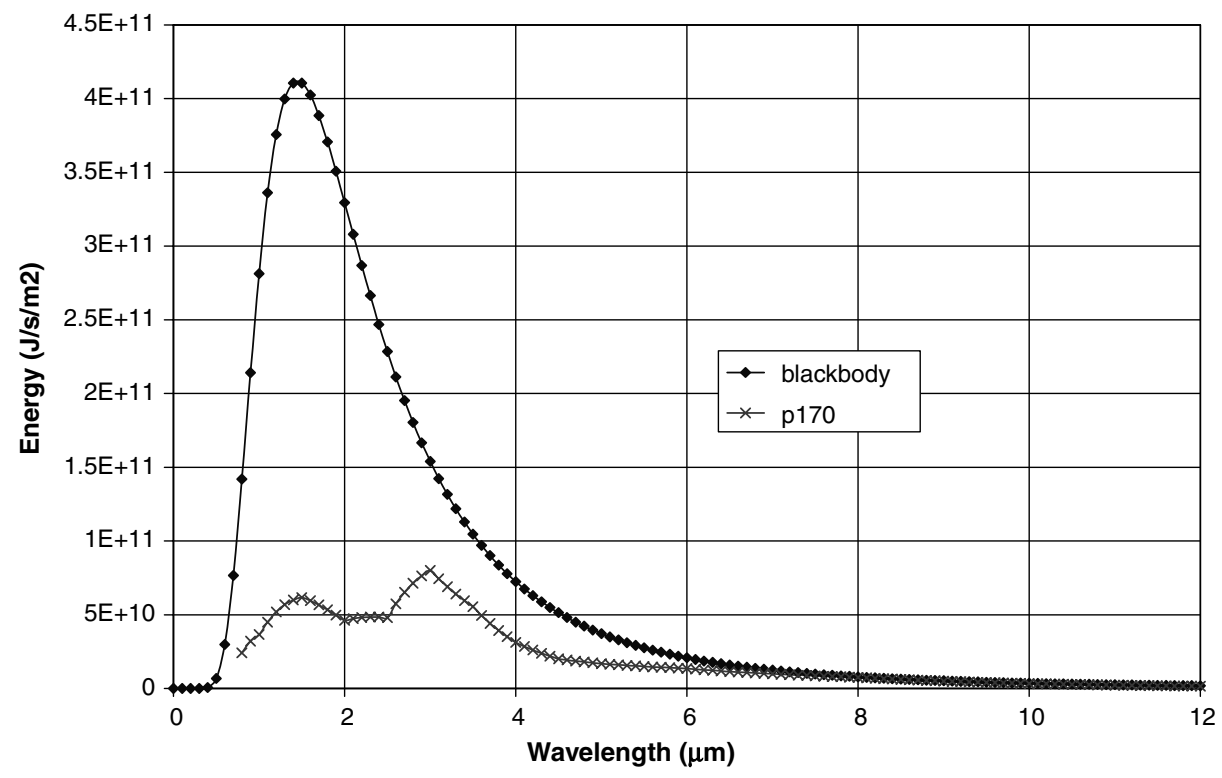

Fig. 5 Spectral radiation for blackbody versus Procelit 170 at $2000 \mathrm{~K}$.

required. To establish the radiation adiabatic temperature of the models, the wind-tunnel flow enthalpy had to be set such that the maximum allowable temperature of P170 was not exceeded. The maximum allowable temperature for P170 is about $2000 \mathrm{~K}$. The wind-tunnel performance settings which were used are given as follows: $p_{0}=560 \mathrm{mbar}, T_{0}=3028 \mathrm{~K}, h_{0}=4.3 \mathrm{MJ} / \mathrm{kg}, m_{\text {air }}=$ $25 \mathrm{~g} / \mathrm{s}, p_{\infty}=0.44 \mathrm{mbar}, T_{\infty}=498 \mathrm{~K}, \rho_{\infty}=2.99 \mathrm{E}-4 \mathrm{~kg} / \mathrm{m}^{3}$, $V_{\infty}=2481 \mathrm{~m} / \mathrm{s}, \quad p t_{0,2}=17.3 \mathrm{mbar}, \quad M_{\infty}=5.45, \quad R e_{\infty}=$ 2.67E4 $(L=1 \mathrm{~m})$, and $\gamma_{\infty}=1.397$. In the table $p_{0}$ represents the wind-tunnel reservoir pressure, $T_{0}$ the wind-tunnel reservoir temperature, $h_{0}$ the wind-tunnel reservoir enthalpy, $p t_{0,2}$ the pitot (stagnation point) pressure, and the $\infty$ symbol indicates freestream properties. $\gamma_{\infty}$ is the specific heat ratio of the freestream flow and $M_{\infty}$ the freestream Mach number.

Accuracies of the measured data are given in Table 3. After establishing the radiation adiabatic temperatures, the cooling was switched on and the temperature drop of the surface of the models could be observed.

First tests were performed with a water mass flow of about $0.5 \mathrm{~g} / \mathrm{s}$. These tests showed that the cooling principle worked very well. On infrared images it can be seen how the water was soaked up in the material and was distributed over the whole model. Because of gravity the bottom part of the model was filled with water first. After the bottom part was filled, water started to flow to the upper regions. The last part to be filled with water was the stagnation point. Here, the pressure of the flow on the model is the highest and therefore the water experiences the highest resistance when flowing into the stagnation point. This explains the relatively long time it takes to wet the stagnation point region. The filling sequence described above can be seen in Fig. 7. Note that the temperature scale changes for each picture.

Also visible in this figure is the extreme cooling from temperatures around $2000 \mathrm{~K}$ to below $488 \mathrm{~K}$. Below $488 \mathrm{~K}$, the infrared camera can no longer measure the temperature. In these regions, the temperature is probably about equal to the boiling temperature of water at the local surrounding pressure. At the stagnation point this local pressure is about 17 mbar. The boiling temperature of water at this pressure is approximately $290 \mathrm{~K}$.

During these tests, an interesting phenomenon was observed; a huge ice beard was formed on the model as illustrated in Fig. $\underline{8}$. This was unexpected, because temperatures in the flow surrounding the model can reach a few thousand degrees. An explanation is found by taking a look at a phase diagram of water [10]. At a pressure of 6 mbar, the triple point is reached. Below this pressure, water can only exist in the solid or gaseous phase. The pressure in the reservoir of the model will be at least equal to the stagnation pressure on the model (17 mbar). Here, the water is in the liquid phase. The local surrounding pressure will vary along the model surface and can drop to as low as 0.44 mbar (see Sec. III.D). When the water reaches the surface at points of low pressure $(<6$ mbar $)$, it undergoes a phase change. Because of the high surrounding temperature, it is expected that vaporization takes place. The vaporization requires a large amount of energy. Thus, when too much water reaches the surface some of the water cannot be vaporized. The water which does vaporize extracts energy from its surroundings, causing the temperature of the liquid water to drop to the freezing temperature, and thus causing the ice beard to form.

To prevent such extreme ice formation, the water mass flow was reduced to $0.2 \mathrm{~g} / \mathrm{s}$. At this flow rate, ice building was still present, but to a much lesser degree. The formation of the ice beard took longer and the beard was much smaller. Constrained by the equipment available, it was not possible to achieve a lower mass flow rate than $0.2 \mathrm{~g} / \mathrm{s}$.

It is noted that the ice formation only occurs because of the extremely low pressure in the wind tunnel. If the cooling system would be applied to a hypersonic vehicle such as the SpaceLiner, pressure during the flight would be sufficiently high to prevent ice formation. Flow separation due to ice formation is therefore not considered to be a hazard.

\section{Test Campaign}

\section{A. Introduction}

Once suitable wind-tunnel settings were determined, the test campaign was started. The water mass flow was kept at the value of $0.2 \mathrm{~g} / \mathrm{s}$ and the wind-tunnel performance was set to the values given in Sec. III.D. All three models were tested but reliable results were only obtained using the models with the largest nose radii (1.75 and $2.5 \mathrm{~cm})$. For the model with the smallest radius $(1 \mathrm{~cm})$, radiation adiabatic temperature became too high and the model showed signs 


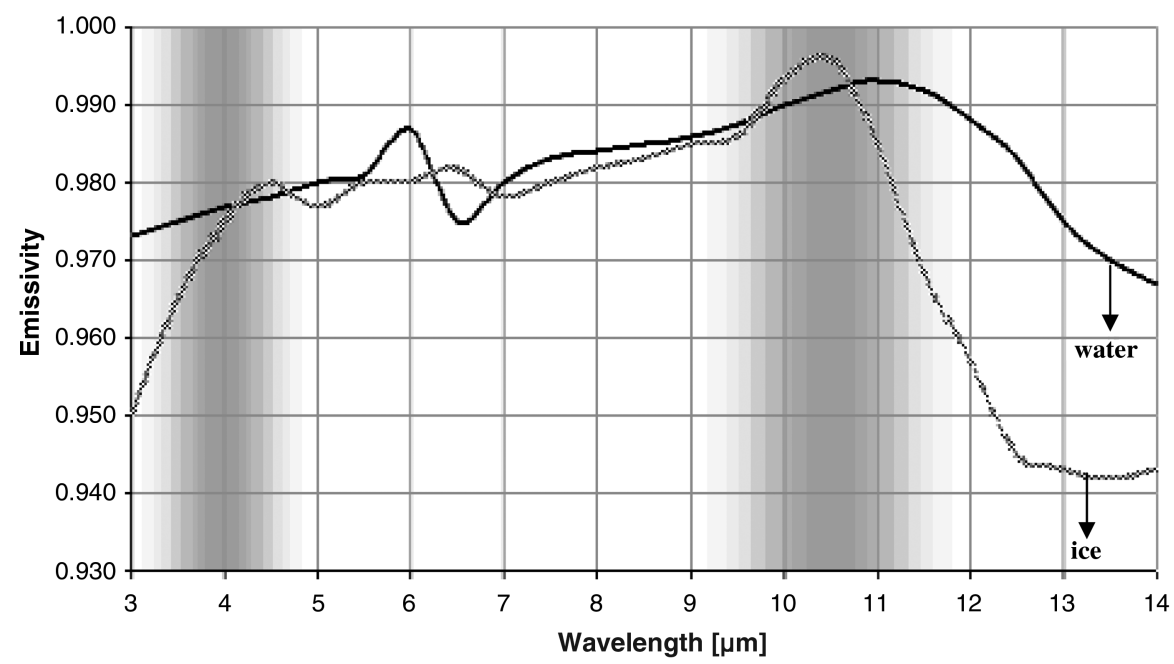

Fig. 6 Spectral emissivity of water and ice [14].

of melting in the stagnation point region. This causes a loss of porosity and therefore water flow was blocked and cooling did not function any longer.

A picture of a test can be seen in Fig. 9. The shock wave can clearly be seen. Also, the model seems to light up as though a light bulb is present in the flow. This is explained by the high reflectivity of Procelit 170 (and thus low emissivity) in the visible part of the electromagnetic spectrum which causes the bright light of the air flow to scatter in all directions.

After carrying out all the tests using liquid water, tests were repeated using nitrogen $\left(\mathrm{N}_{2}\right)$ gas as coolant. Different coolant gas mass flows were tried out. These tests were performed to allow comparison of the efficiency of using water as a coolant against the "traditional" transpiration cooling efficiency using a gas.

\section{B. Test Results}

Test results of cooling using the model with nose radius of $2.5 \mathrm{~cm}$ are presented here. Figure 10 shows an infrared image of the temperatures in the radiation adiabatic case. As can be seen temperatures in the stagnation point reach values of over $2040 \mathrm{~K}$. The right part of the image represents the behavior of the temperature over time in certain spots on the model when using water cooling. Each line in this figure corresponds to a point on the model indicated by a cross in the left part of the figure. SP01 corresponds to the cross in the stagnation point. SP02 to SP06 correspond to crosses more downstream on the model, with SP06 being the most backward point. The water mass flow rate was $0.2 \mathrm{~g} / \mathrm{s}$. Time is presented in minutes. What can be seen is that the whole model is eventually cooled to temperatures below $500 \mathrm{~K}$. The infrared camera is not able to measure temperatures lower than this value. It is expected that in these regions the temperature will be equal to the boiling temperature of the water (which is about $290 \mathrm{~K}$ at wind-tunnel conditions).

Complete cooling of the model takes about $20 \mathrm{~min}$. This would present a difficulty in real flight applications, because cooling would have to be switched on before reentry. Predicting the time it takes to wet the model is difficult as this depends on a lot of factors such as material thickness, porosity, and pressure difference over the material. Also the geometry of the cooled surface and acceleration of

\section{Table 3 Measurement accuracy}

\begin{tabular}{lc}
\hline \hline Gas mass flow rate, $\mathrm{g} / \mathrm{s}$ & $25 \pm 0.25$ \\
Reservoir pressure, mbar & $560 \pm 5.6$ \\
Specific enthalpy, MJ/kg & $4.32 \pm 0.281$ \\
Total temperature, K & $3028 \pm 66$ \\
Surface temperature measurement accuracy, $\%$ & $\pm 2 \%$ \\
Temperature measurement inaccuracy due to & $\pm 1.1 \%$ \\
$\quad$ emissivity uncertainty of 2\% & \\
\hline
\end{tabular}

the vehicle could have an influence. There are some possibilities to shorten or control the time needed to achieve complete cooling. The material thickness could be adapted or a backpressure could be applied to increase the water mass flow through the material.

The surface temperature development in the same spots using $1 \mathrm{~g} / \mathrm{s}$ of nitrogen can be seen in Fig. 11. In this case the stagnation point cools down to about $1500 \mathrm{~K}$. So even for a 5 times higher gas mass flow as compared to the water mass flow, the temperature drop is still much smaller. On the right-hand side of the figure it can be seen that when the mass flow rate of the gas is equal to that of the water $(0.2 \mathrm{~g} / \mathrm{s})$, the temperature drops are extremely small, especially in stagnation point regions. An overview of the test results is presented in Table 4. It is clear that using liquid water as a coolant is extremely effective compared to cooling with nitrogen gas. Water as a coolant therefore saves coolant mass compared to using nitrogen gas as a coolant.

During all the water cooling tests it was observed that when the model is completely wetted, the stagnation point region is cooled to the lowest temperatures (Fig. 12). A probable explanation is that in the stagnation point the surrounding pressure is higher than the triple point pressure and liquid water can exist. Here, the material cools down to the boiling temperature of the water. At regions located more downstream the surrounding pressure can drop below the triple point pressure $(<6$ mbar) and no liquid water can exist. The water flows from a region with relatively high pressure (the reservoir inside the model where pressure is about 17 mbar) to a region of low pressure. Somewhere in the material, the surrounding pressure will reach the triple point. Ice and water vapor are formed (as also described in Sec. III.D), but in this case no beard is formed because of the reduced water mass flow. Almost all the liquid water will turn into vapor. Because the water vapor forms inside the material and not at the surface, the water vapor heats up and therefore the model is not cooled efficiently and the surface temperature will rise. In Fig. 13 a cross-sectional view of a model is presented, which clarifies the explanation given above.

\section{A. Determining the Heat Flux}

\section{Numerical Analysis}

Transpiration cooling using liquid water has been proven to be much more efficient compared to gas cooling. To be able to make predictions of the required water mass flow for cooling, the results have to be quantified. The first step is to determine the heat flux into the model. Assuming all the heat will be absorbed by the water, the heat flux directly determines the evaporation rate of the water and therefore the required water mass flow. Because heat flux was not measured during the tests, it has to be determined numerically. The DLR program HOTSOSE [11] was used for this. HOTSOSE uses the equilibrium gas model to account for real gas effects. In reality, the gas is not in equilibrium. The flow is strongly frozen and 


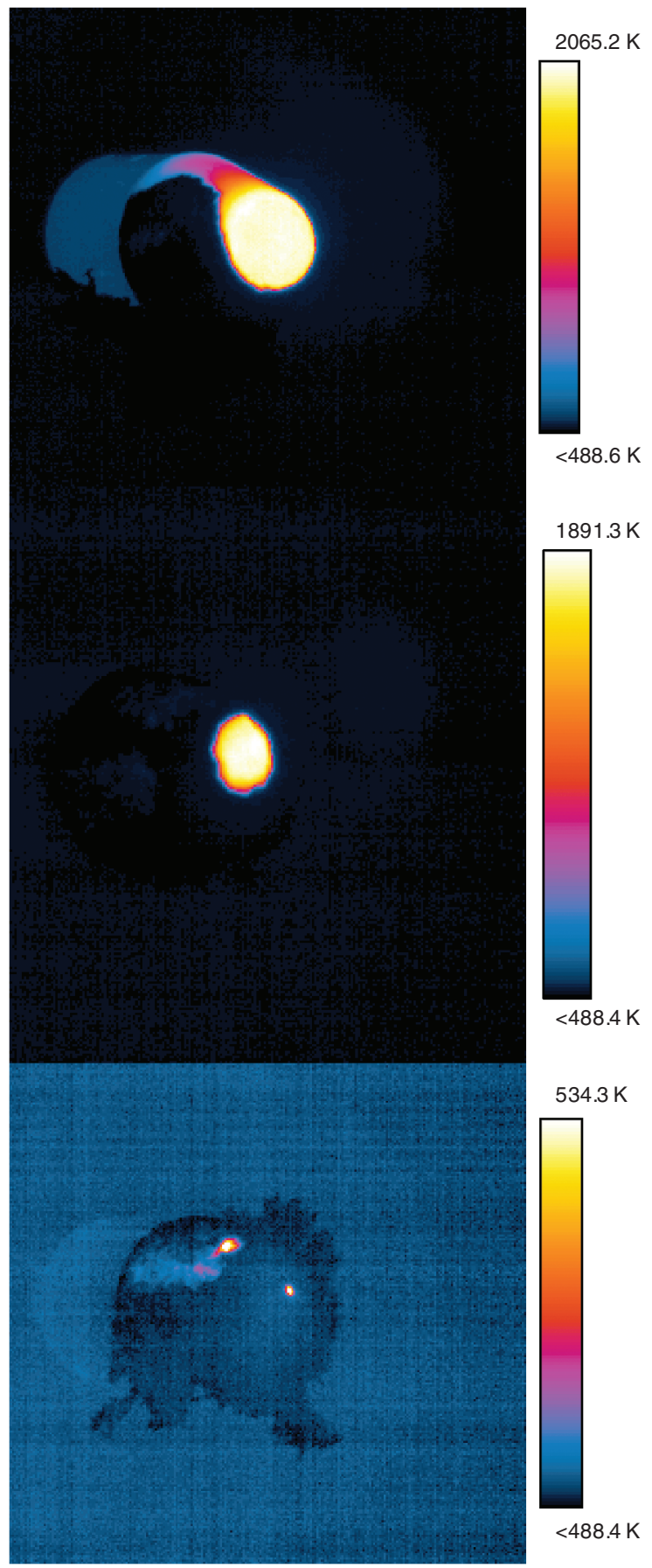

Fig. 7 Infrared image sequence of water filling (image sequence shows model at different times during water filling, with time increasing from top to bottom) [1] .
Procelit 170 is a strongly catalytic material. A frozen flow is exactly the opposite of an equilibrium flow. However, a catalytic surface means that the properties of the model material will cause the reaction rate of the air molecules to increase at the surface, such that equilibrium conditions will be achieved. Figure 14 shows the heat transfer rate $N u / \sqrt{R e}$ into a wall as a function of the recombination rate parameter $C_{1}$. A large $C_{1}$ corresponds to an equilibrium flow and a small $C_{1}$ to a frozen flow. For a catalytic wall, the heat transfer is independent of the recombination parameter. For equilibrium flow (the right part of Fig. 14), heat will be transferred by conduction into the wall. For both equilibrium flow and frozen flow the heat transfer rate will be the same. The equilibrium gas model therefore seems to be a good approximation for calculating the heat flux into the model wall.

Numerical calculations for heat fluxes at wind-tunnel conditions are presented in Fig. 15. For reasons of simplicity these calculations do not include the blocking effect. In Fig. 15 the $x$ axis represents the distance along the centerline of the model (see also Fig. 3) and the $y$ axis represents the heat flux in $\mathrm{W} / \mathrm{m}^{2}$ at the surface of the model. Note that in the case of radiation adiabatic conditions (cooling switched off) the heat flux into the model is much smaller than in the case of a cooled wall. Cooling decreases the temperature but increases the heat flux into the model. Heat flux into the model depends largely on the difference between the enthalpy of the gas at the boundary-layer edge and the enthalpy directly at the wall $\left(h_{e}-h_{w}\right)$. In case of a cooled wall the enthalpy directly at the wall will become smaller and heat flux increases.

During the tests the model is cooled down to about $300 \mathrm{~K}$. Therefore this line is representative for the test conditions. By integrating the heat flux over the cooled surface of the model, the total heat flow into the model is obtained. For the cooled wall, this results in $578 \mathrm{~W}$. At $300 \mathrm{~K}$ the heat lost due to radiation is minimal. Virtually all this heat will be absorbed by the water.

During testing, the total pressure in the wind tunnel is low (17 mbar). At this pressure, water boils at about $17^{\circ} \mathrm{C}$, which is only slightly above the initial temperature of the water when it enters the model. In this case the energy required to heat the water up to the boiling temperature can be neglected. Only the heat of vaporization is of importance. By assuming that all the heat is absorbed by the water, water consumption can be calculated as follows:

$$
\dot{m}=\frac{Q_{\text {in }}}{H_{\text {vap }}}
$$

where $\dot{Q}_{\text {in }}$ is the heat flow $[W]$ into the material, $\dot{m}$ is the water mass flow in $\mathrm{kg} / \mathrm{s}$, and $H_{\text {vap }}$ is the heat of vaporization of water $(2460 \mathrm{~kJ} / \mathrm{kg}$ at wind-tunnel conditions).

A required water mass flow of $0.235 \mathrm{~g} / \mathrm{s}$ is calculated. This is close to the $0.2 \mathrm{~g} / \mathrm{s}$ of the water flow rate which was applied during the test (a difference of 14.9\%). It has already been mentioned in Sec. III.C that the $0.2 \mathrm{~g} / \mathrm{s}$ mass flow was already more than needed to cool down the model, but that it was not possible to reduce this mass flow further given the available experimental hardware. The actual difference between the numerically calculated water mass flow and

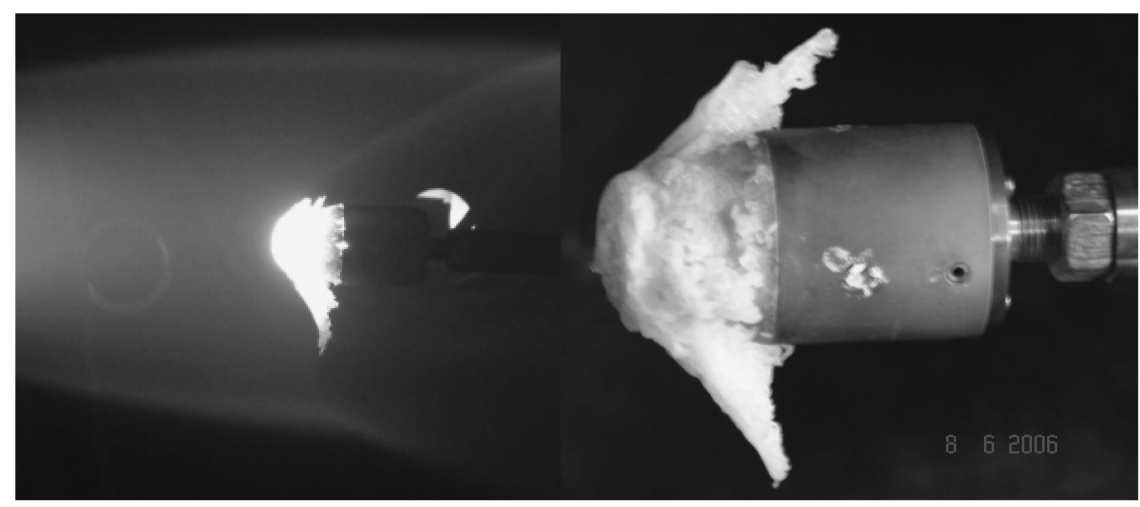

Fig. 8 Ice beard in hypersonic, high temperature flow [1] $]$ 


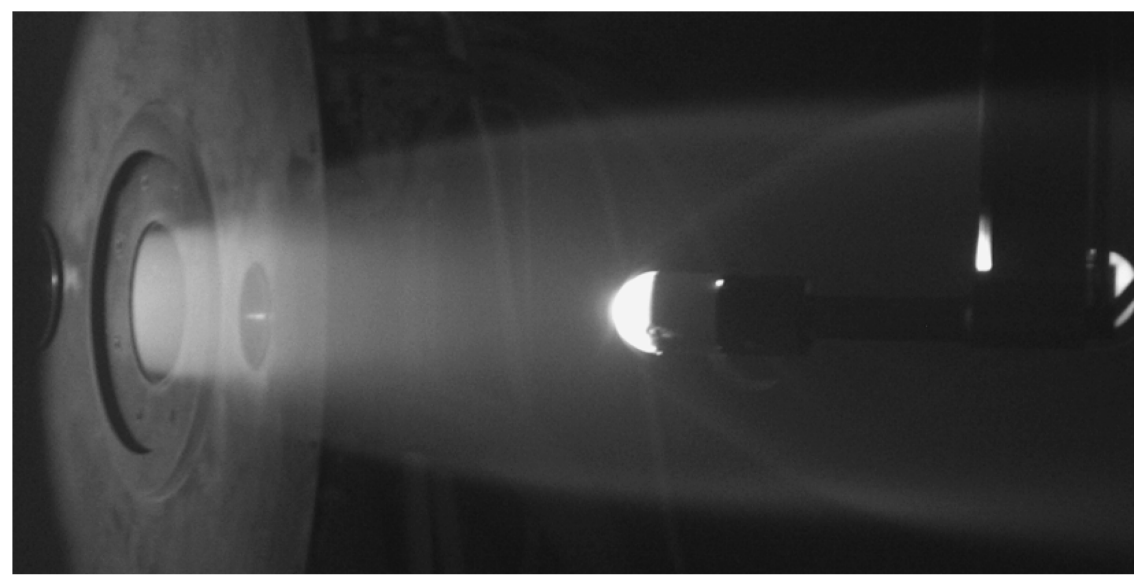

Fig. 9 Test in L2K arc heated wind tunnel [1] $]$.
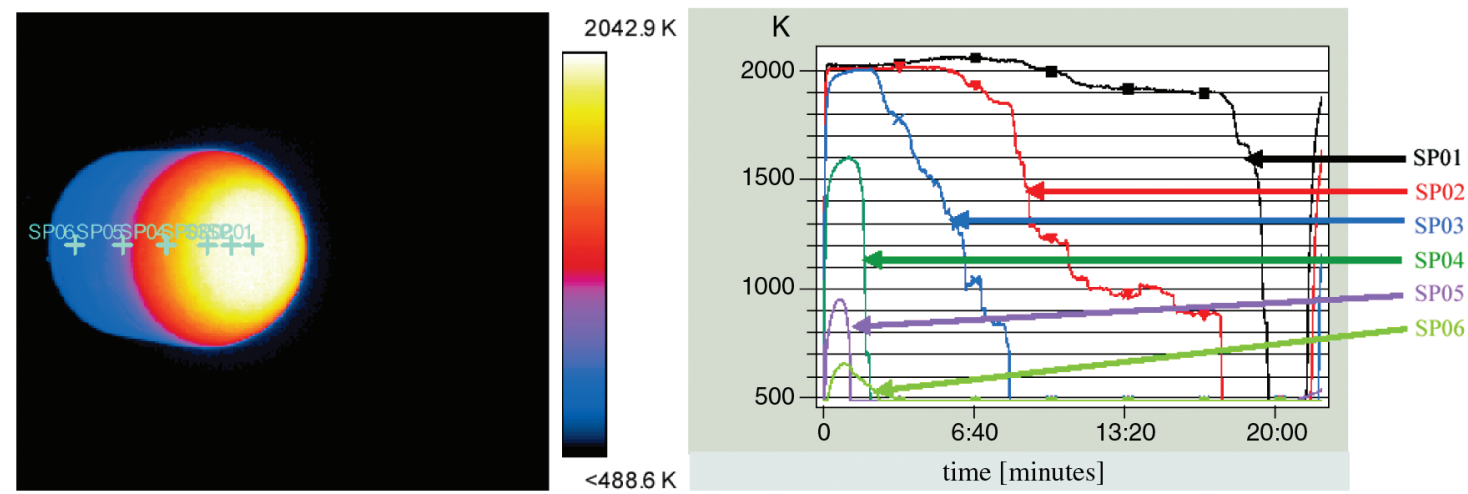

Fig. 10 Test results using $0.2 \mathrm{~g} / \mathrm{s}$ liquid water [1]

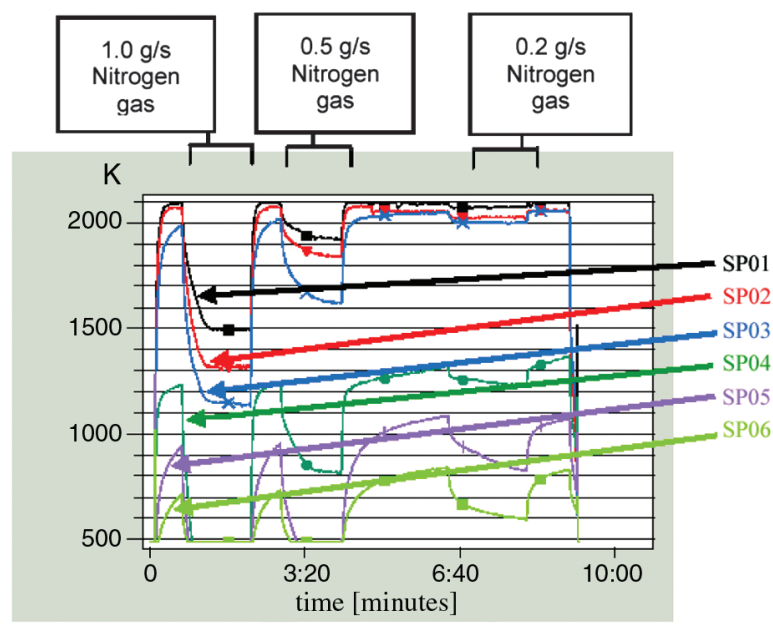

Fig. 11 Test results using nitrogen gas [1] $]$. the actual water mass flow required to cool down the model is therefore more than $14.9 \%$. Additional experiments were executed to determine exactly how big the difference is between the calculations and the measurements.

\section{B. Additional Experiments}

For the additional experiments the water mass flow was set to $0.24 \mathrm{~g} / \mathrm{s}$. The wind-tunnel flow enthalpy was increased stepwise to determine the maximum flow enthalpy at which the complete model could be cooled down. These flow conditions are as follows: $p_{0}=800 \mathrm{mbar}, T_{0}=3906 \mathrm{~K}, H_{0}=7.54 \mathrm{MJ} / \mathrm{kg}, m_{\mathrm{air}}=$ $30 \mathrm{~g} / \mathrm{s}, \quad p_{\infty}=0.5561 \mathrm{mbar}, \quad T_{\infty}=554 \mathrm{~K}, \quad \rho_{\infty}=3.038 \times$ $10^{-4} \mathrm{~kg} / \mathrm{m}^{3}, V_{\infty}=2925 \mathrm{~m} / \mathrm{s}, M_{\infty}=5.719$, and $R e_{\infty}=3.153$ $\times 10^{4}$. The heat flux along the model is calculated numerically and is shown in Fig. 16. The data in this table and figure apply to the model with $0.025 \mathrm{~m}$ radius.

The integrated heat flux over the complete model surface results in $850 \mathrm{~W}$. From Eq. (1) it follows that the resulting water usage is $0.346 \mathrm{~g} / \mathrm{s}$. The difference is $0.106 \mathrm{~g} / \mathrm{s}$, or $31 \%$. Similar tests with the models with radius $0.0175 \mathrm{~m}$ resulted in a difference of $30 \%$ [1].

Table 4 Comparison between gas and liquid water as coolants [

\begin{tabular}{ccccc}
\hline \hline & $\begin{array}{c}\text { Temperature drop using } \\
0.2 \mathrm{~g} / \mathrm{s} \text { water }\end{array}$ & $\begin{array}{c}\text { Temperature drop using } \\
0.2 \mathrm{~g} / \mathrm{s} \text { nitrogen gas }\end{array}$ & $\begin{array}{c}\text { Temperature drop using } \\
0.5 \mathrm{~g} / \mathrm{s} \text { nitrogen gas }\end{array}$ & $\begin{array}{c}\text { Temperature drop using } \\
1 \mathrm{~g} / \mathrm{s} \text { nitrogen gas }\end{array}$ \\
\hline SP01 & $>1500 \mathrm{~K}$ & $0 \mathrm{~K}$ & $200 \mathrm{~K}$ & $600 \mathrm{~K}$ \\
SP02 & $>1500 \mathrm{~K}$ & $50 \mathrm{~K}$ & $250 \mathrm{~K}$ & $800 \mathrm{~K}$ \\
SP03 & $>1500 \mathrm{~K}$ & $100 \mathrm{~K}$ & $400 \mathrm{~K}$ & $850 \mathrm{~K}$ \\
SP04 & $>1100 \mathrm{~K}$ & $100 \mathrm{~K}$ & $400 \mathrm{~K}$ & $>700 \mathrm{~K}$ \\
SP05 & $>450 \mathrm{~K}$ & $300 \mathrm{~K}$ & $>450 \mathrm{~K}$ & $>400 \mathrm{~K}$ \\
SP06 & $>160 \mathrm{~K}$ & $250 \mathrm{~K}$ & $>200 \mathrm{~K}$ & $>200 \mathrm{~K}$ \\
\hline \hline
\end{tabular}



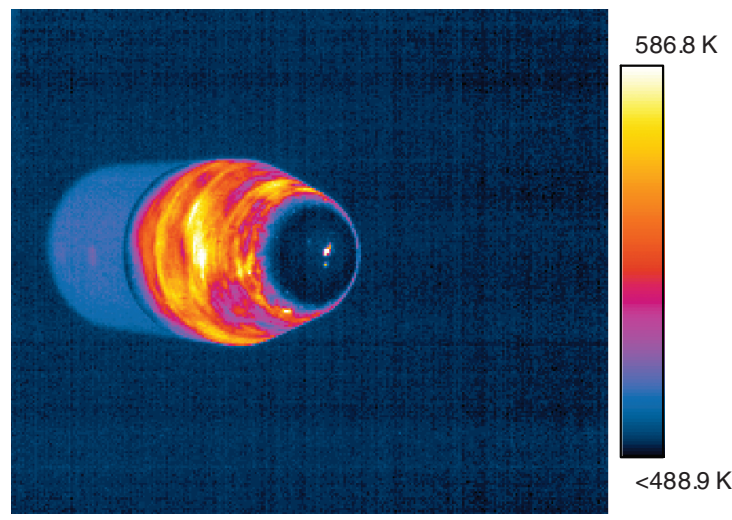

Fig. 12 Cooled model temperature distribution [1].

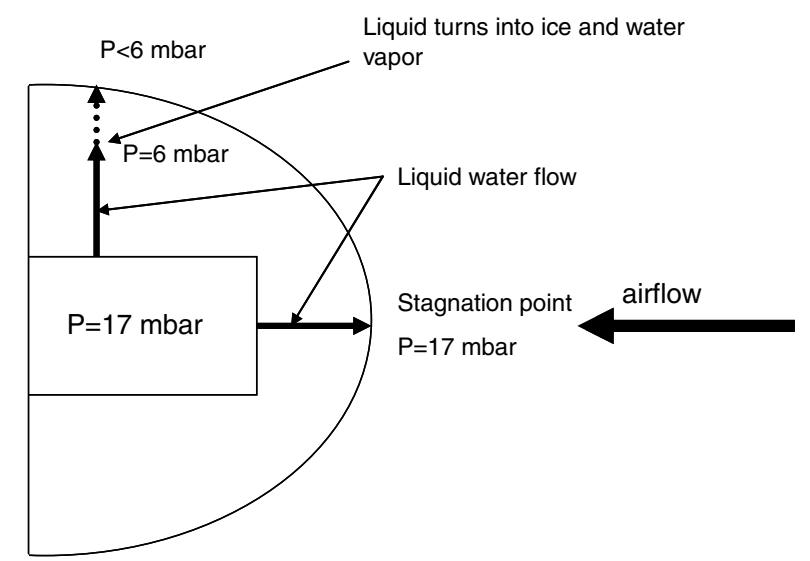

Fig. 13 Schematic explanation of cooled model temperature distribution.

The neglecting of the blocking effect in the calculations is probably responsible for at least part of this difference but more detailed investigation is needed to verify this hypothesis.

\section{Future Improvements}

\section{A. Reducing the Water Usage}

A number of potential methods exist to reduce the water usage for cooling. The first method is to make the nose and leading edge radii smaller. This reduces the surface area that needs to be cooled. A smaller nose radius also leads to an increase in heat flux. It can be shown mathematically that the smaller area outweighs the increased heating.

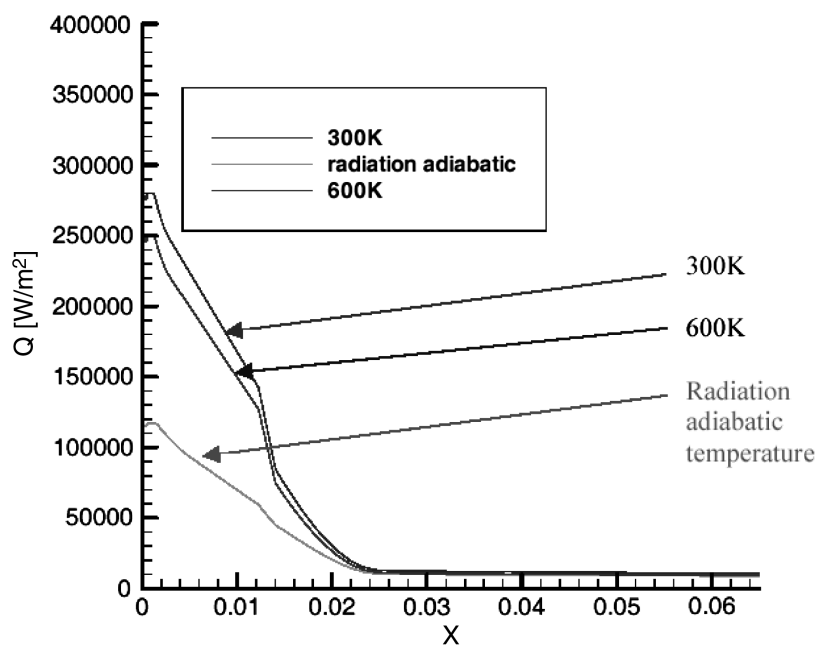

Fig. 15 Heat flux along the surface of the model [1]

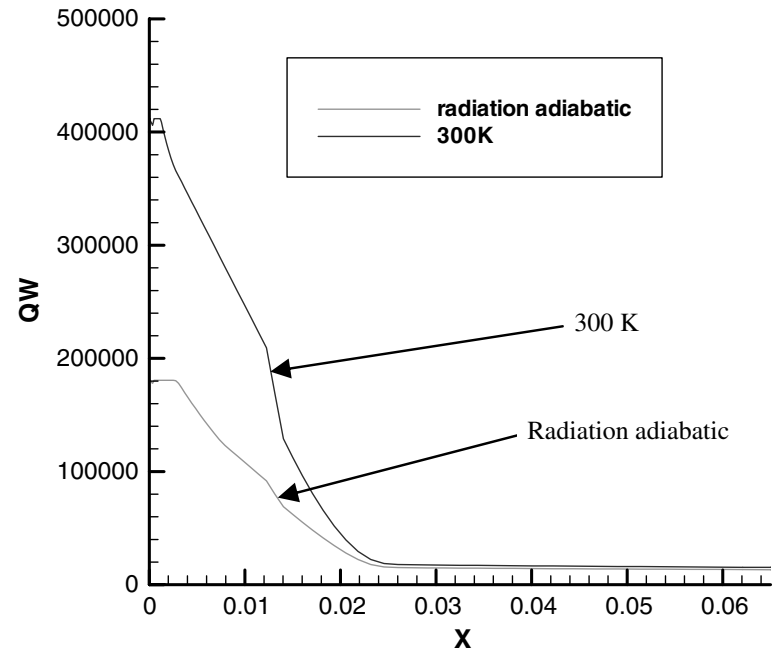

Fig. 16 Heat flux along the surface of the model at maximum windtunnel performance for $0.24 \mathrm{~g} / \mathrm{s}$ water mass flow. The data apply to the model with the $0.025 \mathrm{~m}$ radius [1] .

Looking at the Fay Riddell equation for stagnation point heating [12], it can be seen that

$$
\dot{q}_{\mathrm{sp}} \hat{=} \frac{1}{\sqrt{R}}
$$

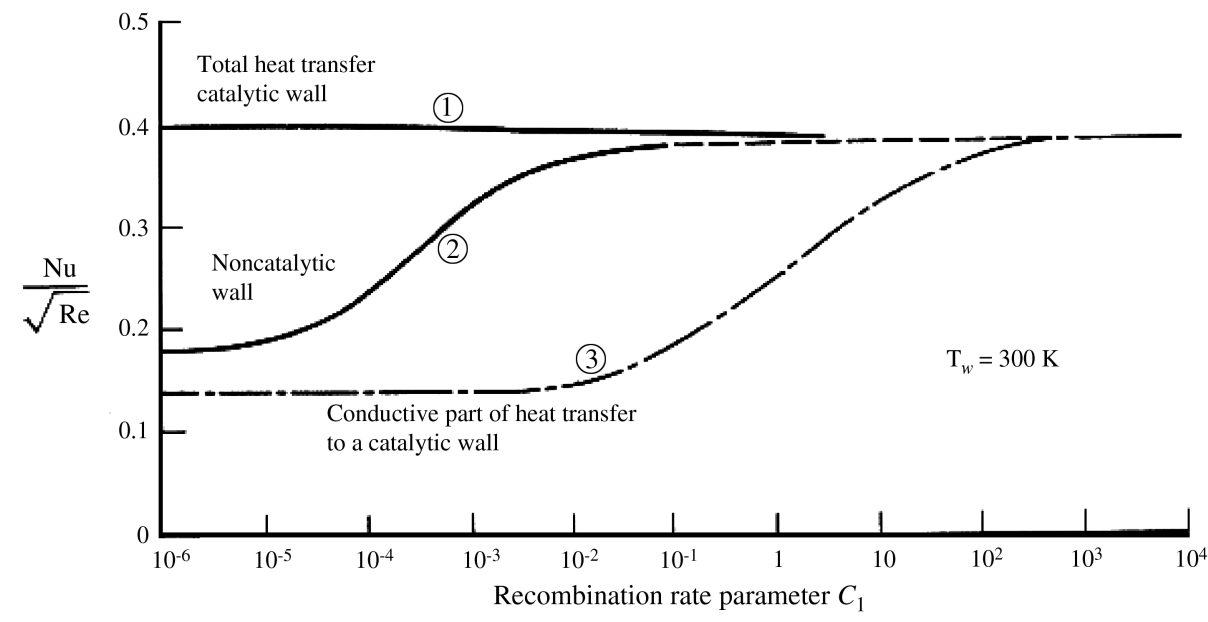

Fig. 14 Heat transfer into wall for different wall catalysis [12]. 


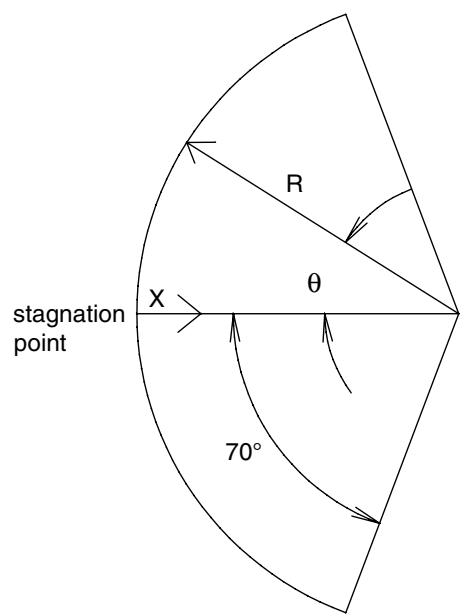

Fig. 17 Definition of $\theta$.

where $\dot{q}_{\mathrm{sp}}$ is the heat flux into the stagnation point in $\mathrm{W} / \mathrm{m}^{2}$ and $R$ is the nose radius in $\mathrm{m}$.

According to [13] the total heat flow into an (almost) half-sphere is given by

$$
\dot{Q}_{\text {total }}=-\left.\frac{4}{5} \pi R^{2} \dot{q}_{\mathrm{sp}} \cos ^{\frac{5}{2}} \theta\right|_{0} ^{\theta}, \quad 0 \leq \theta \leq 70 \mathrm{deg}
$$

where $\dot{Q}_{\text {total }}$ is the total heat flow into the half-sphere in $W$ and $\theta$ is defined in Fig. 17.

Inserting (2) into (3) yields

$$
\dot{Q}_{\text {total }} \hat{=}-\left.\frac{4}{5} \pi R^{1.5} \cos ^{\frac{5}{2}} \theta\right|_{0} ^{\theta}, \quad 0 \leq \theta \leq 70 \mathrm{deg}
$$

One can clearly see that the smaller the radius, the smaller the total heat flow into the nose and the smaller the water usage. The total heat flow and thus water usage is shown to be proportional to $R^{1.5}$.

For a leading edge the result is [1]

$$
\left.\dot{Q}_{\text {total }} \hat{=} 2 L \sqrt{R} \sin \theta\right|_{0} ^{70}
$$

In case of a leading edge the total heat flow and thus water usage is shown to be proportional to $\sqrt{R}$.

A second method for water reduction is to reduce the cold wall heat flux. This can be done by covering the porous material (such as Procelit 170) with a perforated skin. This skin would then heat up, and heat is transferred into the porous material via conduction in this skin. By choosing a material with a suitable conductivity, the skin can be allowed to heat up to a certain temperature, thus decreasing the cold wall heat flux. Perforating the skin allows water evaporated in the porous material to escape through the holes in the skin into the boundary layer, thus still being able to use the blocking effect. Figure 18 shows a schematic drawing of this concept. Alternatively, a material with less porosity could be used. The material would thus heat up to higher temperatures, reducing the cold wall heat flux.

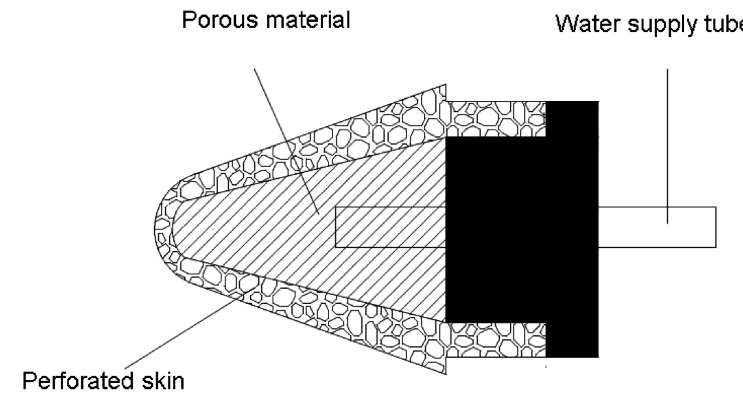

Fig. 18 Cooled nose with perforated skin.

\section{B. Potential Materials to be Used}

The Procelit 170 material used during the tests is far too brittle to be used to make a nose or a leading edge for a hypersonic vehicle. Under high loading or in case of a foreign object impact the material would suffer serious damage. A protective layer would have to be placed over the Procelit preventing it from damage. Such a layer can have the additional advantage of reducing the cold wall heat flux, as mentioned above.

Another option is to use a porous material which is stronger and less brittle. Ceramic matrix composites, such as $\mathrm{C} / \mathrm{C}$ and $\mathrm{C} / \mathrm{C}-\mathrm{SiC}$ are interesting. These materials are very strong. They also have the property that during manufacturing the porosity can be varied, making it possible to reduced the cold wall heat flux and save cooling water.

Temperature resistance of $\mathrm{C} / \mathrm{C}$ is not very high in oxidizing atmospheres $\left(450^{\circ} \mathrm{C}\right) . \mathrm{C} / \mathrm{C}-\mathrm{SiC}$ can withstand temperatures of up to $1750^{\circ} \mathrm{C}$.

\section{Conclusions}

Water cooling is demonstrated to be extremely effective. The models are cooled down from temperatures over $2000 \mathrm{~K}$ to temperatures lower than $300 \mathrm{~K}$, using only little amounts of water. Compared to transpiration cooling using a gas (in this case nitrogen), a water mass flow of only $0.2 \mathrm{~g} / \mathrm{s}$ cools the models down to much lower temperatures than is achieved for gas cooling. Even a gas coolant mass flow 5 times as high does not reduce the temperatures to the same level.

Numerical predictions of water usage result in an overestimation of the water usage of up to $31 \%$. A factor which could be responsible for this difference could be the neglecting of the blocking effect in the numerical calculations. More testing is needed to verify this.

Numerical analyses of the tests show that cold wall heat fluxes are much higher than radiation adiabatic heat fluxes. Water mass flow can therefore potentially be reduced by letting the surface of the material heat up. Alternatively, the water mass flow could be reduced by using a material with less porosity. Potential materials are $\mathrm{C} / \mathrm{C}$ or $\mathrm{C} / \mathrm{C}-\mathrm{SiC}$ which can withstand high temperatures and are very strong. Porosity of these materials can be varied during manufacturing.

\section{References}

[1] Van Foreest, A., "Investigation on Transpiration Cooling Methods for the SpaceLiner," DLR IB647-2006/05, SART TN-004/2006, 2006

[2] Van Foreest, A., "Trajectory Analysis and Preliminary Design of a Future Spacecraft for Intercontinental Rocket Powered Passenger Travel," DLR, SART TN-008/2005, 2005.

[3] Van Foreest, A., Sippel, M., Klevanski, J., Gülhan, A., and Esser, B., "Technical Background and Challenges of the SpaceLiner Concept," 7th International Symposium on Launcher Technologies, CNES, Evry, France, April 2007.

[4] Sippel, M., Klevanski, J., van Foreest, A., Guelhan, A., Esser, B., and Kuhn, M., "The SpaceLiner Concept and its Aerothermodynamic Challenges," Arcachon Conference, IAA, Paris, France, 2006.

[5] Sippel, M., Klevanski, J., and Steelant, J., "Comparative Study on Options for High-Speed Intercontinental Passenger Transports: AirBreathing-vs. Rocket Propelled," IAC-05-D2.4.09, Oct. 2005.

[6] Sippel, M., "Introducing the SpaceLiner Vision," 7th International Symposium on Launcher Technologies, CNES, Evry, France, April 2007.

[7] Kuhn, M., Hald, H., Gülhan, A., and Esser, B., "Experimental Investigations of Transpiration Cooled CMC's in Supersonic Plasma Flows," 5th European Workshop on Thermal Protection Systems and Hot Structure, ESA/ESTEC, Noordwijk, 17-19 May 2006.

[8] Richardson, M., "Theory and Practice in Capillary Force Vaporizer Devices," Vapor Inc. 510-235- 4911, 20 May 2004

[9] Gülhan, A., Esser, B., and Koch, U., "Experimental Investigation on Local Aerothermodynamic Problems of Re-Entry Vehicles in the Arc Heated Facilities LBK," Journal of Spacecraft and Rockets, Vol. 38, No. 2, March-April 2001, pp. 199-206. doi: $10.2514 / 2.3670$

[10] Moran, M. J., and Shapiro, H. N., Fundamentals of Engineering Thermodynamics, Wiley, Chichester, West Sussex, England, U.K., 2000, 3rd ed. 
[11] Reisch, U., and Anseaume, Y., "Validation of the Approximate Calculation Procedure HOTSOSE for Aerodynamic and Thermal Loads in Hypersonic Flow with Existing Experimental and Numerical Results," DLR, Institut für Entwurfsaerodynamic Braunschweig, Forschungsbericht 98-23, 1998.

[12] Anderson, J. D., Jr., Hypersonic and High Temperature Gas Dynamics, McGraw-Hill, New York, 1989.
[13] Buursink, J., On the Development of a Water-Cooled Metallic Thermal Protection System, TU Delft, The Netherlands, 2005.

[14] MODIS UCSB emissivity library, http://www.icess.ucsb.edu/modis/ EMIS/html/em.html.

[15] Procelit 170 emissivity data sheet, Thermal Ceramics (department Kapyrok), Lillebonne, France. 